\title{
Telemedicine Home-Based Cardiac Rehabilitation
}

\author{
A CASE SERIES
}

\author{
Robert Berry, MS; Clinton A. Brawner, PhD; S. George Kipa, MD, MS; Courtney Stevens, MsEM; \\ Charles Bloom, DO; Steven J. Keteyian, PhD
}

\begin{abstract}
Details of the Clinical Case: In this case series report, we review 2 patients who were among the first to participate in the Henry Ford telemedicine home-based cardiac rehabilitation (TM-HBCR) program. These patients had barriers to full participation in a facility-based cardiac rehabilitation (CR) program due to return to work and access to transportation. However, they were willing and able to participate in the TM-HBCR program.
\end{abstract}

Discussion: The two cases discussed herein are examples of individuals who likely would not have fully participated in CR if the only option available was a facility-based program. While HBCR is not an option for all patients, it does address several barriers that are known to limit participation in facility-based CR for some individuals.

Summary: Technology has made it possible to provide the key components of a facility-based CR program through a TM-HBCR model using a secure connection to the patients via their personal mobile device.

Key Words: exercise training $\bullet$ heart disease $\bullet$ home-based cardiac rehabilitation $\bullet$ telehealth

he utilization of cardiac rehabilitation (CR) remains
low. In the United States between 2007 and 2011 , CR
participation rates among beneficiaries of Medicare and the
Veteran's Administration averaged $16 \%$ and $10 \%$, respec-
tively, with significant variation by state. ${ }^{1}$ One aim of the
Million Hearts ${ }^{\mathrm{TM}}$ initiative is to improve participation in
CR to $70 \% .^{2}$ To achieve this, barriers to participation (eg,
access to CR $)^{3}$ must be successfully addressed, which may
include alternate strategies for delivering CR.,5
A home-based CR (HBCR) program with synchronized,
remote monitoring by a clinician (ie, telemedicine [TM])
represents one delivery model that targets several barri-
ers. ${ }^{5}$ In a telemedicine home-based cardiac rehabilitation
(TM-HBCR) program, patients exercise at a location that
is convenient to them (eg, home and/or fitness facility),
while they simultaneously interact with a clinician via
audio/video. Despite expanding availability of TM infra-
structure, as well as increased application in other areas of
health care, TM-HBCR has largely been limited to clinical

Author Affiliations: Division of Cardiovascular Medicine, Henry Ford Hospital, Detroit, Michigan (Mr Berry and Drs Brawner and Keteyian); Blue Cross Blue Shield of Michigan, Detroit, Michigan (Dr Kipa); Virtual Care, Henry Ford Health System, Detroit, Michigan (Ms Stevens); and Health Alliance Plan, Detroit, Michigan (Dr Bloom).

Supplemental digital content is available for this article. Direct URL citation appears in the printed text and is provided in the HTML and PDF versions of this article on the journal's Web site (www.jcrpjournal.com).

The authors declare no conflicts of interest.

Correspondence: Robert Berry, MS, Division of Cardiovascular Medicine; Henry Ford Hospital, 6525 Second Ave, Detroit, Ml 48202 (rberry5@hfhs.org). Copyright $\odot 2020$ Wolters Kluwer Health, Inc. All rights reserved. DOI: 10.1097/HCR.0000000000000504 trials. ${ }^{6,7}$ This is partly due to the lack of reimbursement for TM-HBCR by the Centers for Medicare \& Medicaid Services and most private health insurance providers in the United States.

In this case series report, we review 2 patients who were among the first to participate in the Henry Ford TM-HBCR program, to discuss how the program was developed and describe the needed technology and procedures.

\section{CLINICAL CASE 1}

Dr TS is a 58-yr-old veterinarian who suffered an ST-elevation myocardial infarction in May 2016. Coronary angiography revealed a chronic total occlusion of the left anterior descending artery with collateral circulation from the right coronary artery. A thrombus occluded the right coronary artery and was treated successfully with thrombectomy and stent. The hospitalization was complicated by cardiogenic shock, requiring mechanical support.

In August 2016, the ejection fraction of the patient was $30-35 \%$ per echocardiogram. He was prescribed aspirin, atorvastatin, clopidogrel, digoxin, and furosemide. His cardiologist ordered a cardiopulmonary exercise (CPX) test and CR. His peak oxygen uptake was $20.6 \mathrm{~mL} \cdot \mathrm{kg}^{-1} \cdot \mathrm{min}^{-1}$. The test was limited by general fatigue, was negative for myocardial ischemia, demonstrated normal heart rate (HR) and blood pressure responses, and there was occasional ventricular ectopy. The patient was started on sacubitril/ valsartan in December 2016 and a cardioverter-defibrillator was implanted in January 2017.

Dr TS was reluctant to start facility-based CR (FBCR) due to program hours conflicting with his veterinary practice. He had been physically active. His only modifiable risk factor was hyperlipidemia. Based on results from his CPX test, he was prescribed an exercise training target $\mathrm{HR}$ range (THRR) of $92-102 \mathrm{bpm}$, which was $50-70 \%$ of measured HR reserve.

Dr TS began CR in September 2016 by first attending 3 electrocardiogram (ECG)-monitored sessions in FBCR. This allowed staff to evaluate his HR and blood pressure responses during exercise before transitioning to HBCR. During FBCR he exercised on a treadmill at a work rate equivalent to an estimated 3.5 metabolic equivalents (METs; $3.3 \mathrm{mph}$ and $0 \%$ ), there were no arrhythmias, and his physiologic responses to exercise were normal.

Dr TS then scheduled two 20-30 min HBCR sessions/ wk during his lunch break. Exercise was performed on his home treadmill. He was instructed to log into the TM-HB$\mathrm{CR}$ visit after completing $\geq 5 \mathrm{~min}$ of warm-up. He was encouraged to complete $\geq 2$ additional $\mathrm{d} / \mathrm{wk}$ of exercise on his own. By week 8 he was exercising at an estimated 4.7 METs.

In February 2017, Dr TS began to incorporate higher intensity interval training on 2 nonconsecutive $\mathrm{d} / \mathrm{wk}$. The work intervals were $3 \mathrm{~min}$ at $90 \% \mathrm{HR}$ reserve and recovery intervals were $2 \mathrm{~min}$ at $70 \% \mathrm{HR}$ reserve. He completed 36 sessions 
of CR (33 in HBCR). At program completion he was exercising 4-5 d/wk at an estimated 8 METs (4.5 mph and 5.5\%). Based on a follow-up CPX test completed in March 2017, his peak oxygen uptake was $33.9 \mathrm{~mL} \cdot \mathrm{kg}^{-1} \cdot \mathrm{min}^{-1}$.

\section{CLINICAL CASE 2}

Mrs SG was an 88 yr old when she suffered an ST-elevation myocardial infarction in September 2016. She underwent an emergent percutaneous coronary intervention involving a thrombectomy and the placement of 3 drug-eluting stents in the mid-to-distal left anterior descending artery. The hospitalization was complicated by acute systolic heart failure requiring an intra-aortic balloon pump. Her left ventricular ejection fraction at the time was $40 \%$. She was referred to CR. Following discharge, she complained of persistent fatigue and generalized weakness. Because of concerns expressed by family members regarding her ability to provide self-care, she was moved into an assisted living facility.

Mrs SG began FBCR in October 2016. However, due to macular degeneration, she was dependent on her children to drive her to $\mathrm{CR}$. She was concerned about the burden this placed on her family and HBCR was offered as an alternative. As a result, a plan was established for her to attend 4 ECG-monitored FBCR sessions to evaluate her fall risk and ability to exercise independently, and then was transitioned to HBCR using exercise equipment available in the assisted living facility.

Her modifiable risk factors were diabetes mellitus, hyperlipidemia, hypertension, obesity, and sedentary lifestyle. CR staff elected not to have her undergo a symptom-limited exercise test and her THRR was set at standing resting HR plus 20-30 bpm. During the FBCR visits, she tolerated exercise well and her blood glucose remained within acceptable limits. During these initial visits, she performed an intermittent protocol on the treadmill utilizing a ratio of $3 \mathrm{~min}$ of work to 2 min of standing rest. Mrs SG's initial exercise training workload on the treadmill was estimated at 2 METs (1.5 mph and $0 \%$ ).

Mrs SG was scheduled for two 20-30 min HBCR sessions/wk. Exercise was performed using a treadmill. With her daughter's smartphone and assistance, she logged into the TM-HBCR visit after completing $\geq 5$ min of warm-up. Mrs SG completed 30 sessions of CR (26 in HBCR). At that time, she was completing $28 \mathrm{~min}$ of continuous treadmill walking, $2 \mathrm{~d} / \mathrm{wk}$, at an estimated $2.8 \mathrm{METs}(2 \mathrm{mph}$ and $1 \%$ ). She walked $\geq 20 \mathrm{~min} 1 \mathrm{~d} /$ wk on her own.

\section{DISCUSSION}

The cases discussed herein are examples of individuals who likely would not have fully participated in CR if the only option was FBCR. While HBCR is not an option for all patients, it does address several barriers that are known to limit participation in FBCR for some individuals.

The Henry Ford Hospital TM-HBCR program allows patients to participate in CR by exercising in their home or community, while being remotely supervised by a clinical exercise physiologist via synchronous audio-video communication. To develop a sustainable program that was not dependent on soft money (eg, grant), there were two important items that had to be addressed.

First, the program had to comply with applicable laws for telehealth services in the state of Michigan; 1 of 38 states with a TM parity law, ${ }^{8}$ which stipulates that services delivered remotely are of equivalent value to those delivered in person and therefore should be reimbursed if specific conditions are met. ${ }^{9}$ Based on Michigan law, a qualifying $\mathrm{TM}$ visit must be conducted in real time using either audio or audio-visual technology. ${ }^{10}$

Second, securing reimbursement from private health insurance payers for TM-HBCR was needed. To that end, CR program staff at Henry Ford Hospital contacted two private health insurance providers in Michigan (Health $\mathrm{Al}$ liance Plan, 570000 members; Blue Cross Blue Shield of Michigan, 4.5 million members) to discuss reimbursement. Both agreed to reimburse HBCR with the understanding that the quality of care and documentation would be identical to FBCR. In addition, they agreed that a daily, immediately available supervising physician would not be required because it was $(a)$ inconsistent with contemporary practice of FBCR in which patients are encouraged to exercise on their own at home on days they are not scheduled to attend FBCR and $(b)$ a service delivered via telehealth. A summary of key points to consider when starting a TM-HBCR are outlined in the Table.

The Henry Ford HBCR program uses the MyChart patient portal-a product of the Epic electronic medical record ([EMR], Epic Systems Corp). In conjunction with the Vidyo plug-in (Vidyo, Inc), this enables a live, synchronous audio-video connection through a secure, Health Insurance Portability and Accountability Act (HIPAA)-compliant virtual private network between the clinician and the patient. HBCR appointments are scheduled within the EMR, similar to other appointments. At the time of the visit, the patient logs in through MyChart and the clinician logs in through the EMR. Audio and video are provided by patient mobile device (eg, smartphone or tablet) and a camera/microphone at clinician workstation. An example of the clinician's and patient's view is shown in the Figure.

HBCR is considered for patients who are eligible for FBCR but express concerns about their ability to attend. The HBCR program is then discussed with those patients to determine whether such a program would be a viable alternative. Patients are asked to complete an exercise test and up to 3 visits in FBCR before transitioning to HBCR.

Once patients are enrolled in HBCR, they are given an HR monitor and instructed on its use. In addition, they are assisted in downloading the MyChart app and logging into the portal. They are scheduled for two 20 min HBCR sessions/wk. Patients log into the MyChart app after completing their warm-up. They are expected to exercise up to $30 \mathrm{~min} / \mathrm{session}$; thus, patients complete their exercise after the $20 \mathrm{~min}$ HBCR session ends. Patients are encouraged to exercise 1-3 additional $\mathrm{d} / \mathrm{wk}$. The frequency of the HBCR sessions may decrease as the patient progresses.

The HBCR program was designed to include all of the core components of FBCR (see Supplemental Digital Content 1, available at: http://links.lww.com/JCRP/A164). In brief, exercise training HR, perceived exertion, and workload data are recorded in real time using a visit encounter template that was developed for use within the EMR. Patient education on pathophysiology, risk factor modification, medication compliance, etc, is facilitated using a series of 28 narrated slide shows (https://www.henryford.com/services/ cardiology/support/cardiac-rehab/home-based-cardiacrehabilitation), each of which is $5-8 \mathrm{~min}$ in duration. The slide show(s) to be reviewed by a patient before their next HBCR session is decided upon by the patient and the CR clinician. Program outcome surveys are completed in person at the start of HBCR and through the MyChart portal at completion, and then routed back to the provider through the EMR. 


\begin{tabular}{|c|c|}
\hline Category & Considerations \\
\hline $\begin{array}{l}\text { Safety and emergency } \\
\text { considerations }\end{array}$ & $\begin{array}{l}\text { Ability to access emergency medical services during a CR session. Location and street address of patient (eg, home, commercial } \\
\text { fitness facility) is confirmed, daily weight and resting HR obtained prior to each session. Patient connects to TM-HBCR session } \\
\text { after completing } 5 \text { min of warm-up }\end{array}$ \\
\hline Efficiency/scheduling & $\begin{array}{l}\text { Sessions are scheduled for a duration of } 20 \mathrm{~min} \text {, with staff assigned to cover 3-hr time blocks/d. Two time blocks/d are available } \\
\text { to accommodate patient availability. Grouping sessions as close together, when feasible, aids in maximizing staff productivity }\end{array}$ \\
\hline $\begin{array}{l}\text { Technology of electronic medical } \\
\text { record }\end{array}$ & Free patient portal app on patient personal mobile device allows for interface with virtual private network for HIPAA compliance \\
\hline \multirow[t]{2}{*}{ Equipment required } & $\begin{array}{l}\text { Patient equipment: Home exercise equipment (eg, treadmill or stationary bike), smartphone or mobile device, HR monitoring } \\
\text { watch (preferred), Wi-Fi (preferred), ear buds (preferred) }\end{array}$ \\
\hline & $\begin{array}{l}\text { Provider equipment: Desktop/laptop computer, electronic medical record with video platform, dual/second monitor screen, web- } \\
\text { cam, headset (preferred) or soundbar }\end{array}$ \\
\hline Patient education & Access to online documents or videos \\
\hline Documentation & $\begin{array}{l}\text { Record exercise modality, duration, workload, peak HR, and RPE. Document any adverse signs and symptoms, if present, and } \\
\text { any actions taken to correct. Develop plan for exercise intensity at next session. Document educational topic discussed along } \\
\text { with patient comprehension of topic. }\end{array}$ \\
\hline Billing & $\begin{array}{l}\text { CPT } 93797 \text { (outpatient CR without continuous ECG monitoring) is billed for each session. Place of Service code of POS } 02 \text { is } \\
\text { appended to denote practitioner furnishing telehealth services from a distant site. For BCBSM, inclusion of the "GT" modifier } \\
\text { to indicate that the service was delivered via interactive audio and video }\end{array}$ \\
\hline Other & $\begin{array}{l}\text { Because HBCR sessions may be conducted in a community fitness facility, it is recommended that the patient wear ear buds } \\
\text { while participating to reduce the ambient noise for both the patient and the provider }\end{array}$ \\
\hline
\end{tabular}

Abbreviations: BCBSM, Blue Cross Blue Shield of Michigan; CR, cardiac rehabilitation; ECG, electrocardiogram; HBCR, home-based cardiac rehabilitation; HIPAA, Health Insurance Portability and Accountability Act; HR, heart rate; RPE, rating of perceived exertion; TM-HBCR, telemedicine home-based cardiac rehabilitation.

\section{View of clinician workstation during a home-based cardiac rehabilitation session}

Computer Monitor-1: View of Patient

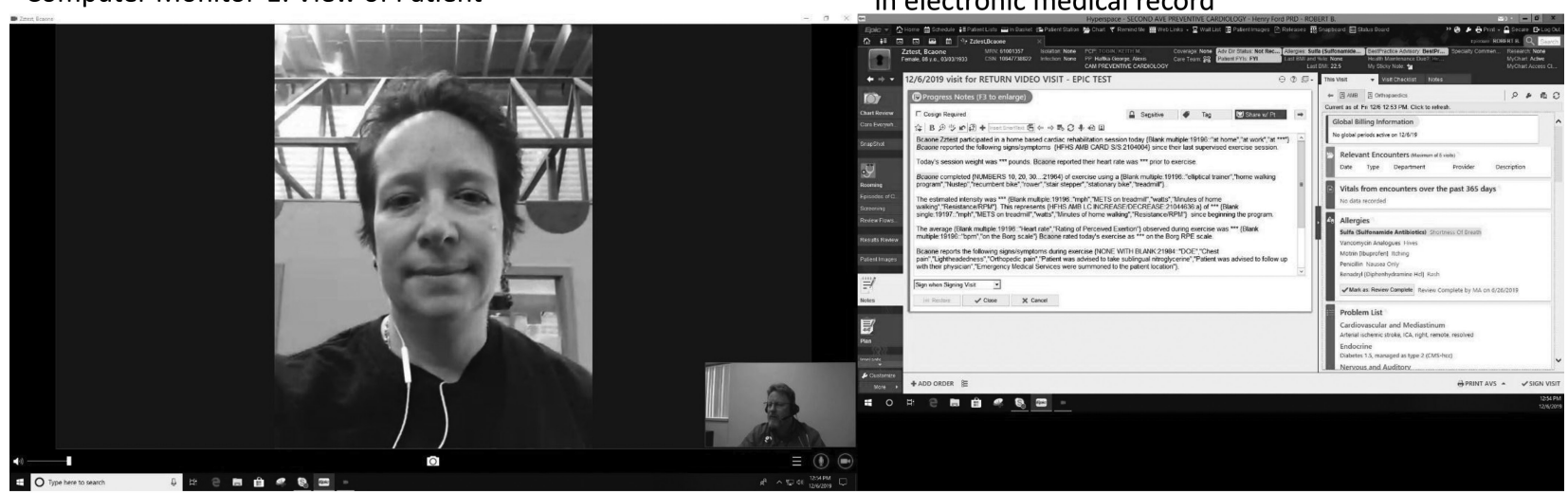

View seen by patient during a home-based cardiac rehabilitation session
Computer Monitor-2: View of progress note template in electronic medical record

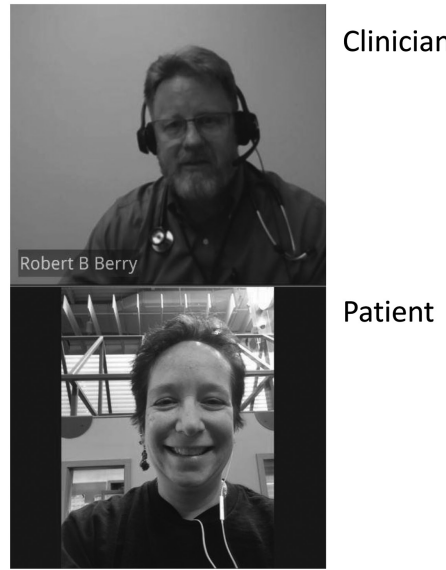

Figure. Image of the clinician (top) and patient view (bottom) during a telemedicine home-based cardiac rehabilitation session.

Copyright $\odot 2020$ Wolters Kluwer Health, Inc. Unauthorized reproduction of this article is prohibited. 
The Henry Ford TM-HBCR program design is not without limitations. These include the 1:1 patient-to-staff ratio, which can be inherently less productive than FBCR. However, scheduling the HBCR sessions for 20 min each allows each clinician to see 3 patients/hr, bringing productivity closer to that of a typical FBCR program. We currently conduct approximately 45 TM-HBCR visits/mo. Developing technology to allow the clinician to conduct multiple HBCR sessions simultaneously is necessary to improve productivity. Another limitation of the model is the inability to quickly respond to adverse events that may occur during exercise. For this reason, each HBCR session begins with confirming patient location and address. Furthermore, the highest risk patients (eg, left ventricular assistive device) are not currently eligible for HBCR. Finally, it is important to state that although specific brand names were used in the text of this article, these only represent the equipment that was available and compatible with existing work processes already in place and should not be construed as an endorsement.

\section{SUMMARY}

Technology has made it possible to provide the key components of an FBCR program (ie, supervised exercise training, education, and outcomes assessment) through a secure connection to the patient using their personal mobile device. Recent scientific reviews suggest that program attendance and outcomes attributable to HBCR are similar to FBCR. ${ }^{5-7}$ Expansion of HBCR across institutions in all states could help increase access and utilization of CR services. That said, it remains appropriate to first strive to enroll all eligible patients into an FBCR program, and then quickly move to discussing HBCR as an option if a patient is not able to participate.

\section{REFERENCES}

1. Beatty AL, Truong M, Schopfer DW, Shen H, Bachmann JM, Whooley MA. Geographic variation in cardiac rehabilitation participation in Medicare and Veterans Affairs populations: opportunity for improvement. Circulation. 2018;137(18):1899-1908.

2. Ades PA, Keteyian SJ, Wright JS, et al. Increasing cardiac rehabilitation participation from $20 \%$ to $70 \%$ : a road map from the Million Hearts Cardiac Rehabilitation Collaborative. Mayo Clin Proc. 2017;92(2):234-242.

3. Schopfer DW, Priano S, Allsup K, et al. Factors associated with utilization of cardiac rehabilitation among patients with ischemic heart disease in the Veterans Health Administration: a qualitative study. J Cardiopulm Rehabil Prev. 2016;36(3):167-173.

4. Balady GJ, Ades PA, Bittner VA, et al. Referral, enrollment, and delivery of cardiac rehabilitation/secondary prevention programs at clinical centers and beyond: a presidential advisory from the American Heart Association. Circulation. 2011;124(25):2951-2960.

5. Thomas RJ, Beatty AL, Beckie TM, et al. Home-based cardiac rehabilitation: a scientific statement From the American Association of Cardiovascular and Pulmonary Rehabilitation, the American Heart Association, and the American College of Cardiology. J Cardiopulm Rehabil Prev. 2019;39(4):208-225.

6. Anderson L, Sharp GA, Norton RJ, et al. Home-based versus centre-based cardiac rehabilitation. Cochrane Database Syst Rev. 2017;6:Cd007130.

7. Hwang R, Bruning J, Morris NR, Mandrusiak A, Russell T. Homebased telerehabilitation is not inferior to a centre-based program in patients with chronic heart failure: a randomised trial.J Physiother. 2017;63(2):101-107.

8. American Telemedicine Association. State Policy Resource Center. http://legacy.americantelemed.org/policy-page/state-policy-resourcecenter. Accessed March 2019.

9. Yang T. Health Policy Brief: Telehealth Parity Laws [published online ahead of print August 15, 2016]. Health Aff. doi:10.1377/ hpb20160815.244795.

10. State of Michigan. Enrolled Senate Bill No.753. Michigan Legislature, 2016. 